\title{
LIBERADOS POR EL PERDÓN, PERO ATADOS POR LA PROMESA.
}

Ana Escríbar Wicks

Profesora Emérita.

Universidad de Chile.

\section{Resumen.}

El trabajo revisa las relaciones entre el perdón, la memoria y el olvido; analiza el uso y posible abuso de estos dos últimos y la conexión existente entre promesa y perdón.

El pensamiento de Paul Ricoeur y el de Hannah Arendt - en lo que respecta a estos temas - aporta los criterios utilizados para la revisión y el análisis.

La exposición se cierra con un breve estudio comparativo de los planteamientos de ambos autores.

Palabras Claves: perdón, memoria, olvido, promesa.

\section{Abstract}

This work examines the relationship between forgiveness, memory and forgetfulness; it analyzes the use and possible abuse of the two last ones and the connection that exists between promise and forgiveness.

The thought of Paul Ricoeur and Hannah Arendt in respect to these matters contributes the criterions used for those revision and analysis.

The exposition ends with a brief comparative study of the statements of both authors.

Key words: Forgiveness, memory, forgetfulness, promise.

\section{1.- Introducción.}

Aunque mi propósito original era desarrollar una reflexión sobre el tema del perdón, al analizar los antecedentes que había reunido sobre dicho tema a través de mi lectura de algunas obras de Paul Ricoeur y Hannah Arendt, llegué a la conclusión de que era aconsejable no abordarlo aisladamente, sino en conexión con la promesa, que para ambos autores se entreteje íntimamente con el perdón y - para Ricoeur - con los temas de la memoria y el olvido.

Considero que los acontecimientos vividos por la humanidad en Europa a lo largo del siglo XX, a los que se suman los acaecidos en nuestro propio país, cuyas repercusiones aún no abandonan la escena pública ni la conciencia ciudadana, hacen innecesario insistir sobre la importancia y actualidad de ambos temas. Por un lado, la del perdón ante un pasado con el que inevitablemente 
debemos saldar cuentas; por otro, la de la promesa como punto de apoyo para el "nunca más" exigido por la tradición de Occidente a partir del la Regla de Oro, con su mandato de no hacer al prójimo lo que no quisiéramos que se nos haga.

Por otra parte, el peso que estos destacados filósofos contemporáneos antes mencionados atribuyen a esos problemas dentro de la vida individual y colectiva, pareciera aconsejar que se acreciente el espacio que hasta este momento se les ha dedicado en nuestra reflexión.

Ricoeur y Arendt son grandes estudiosos de Nietzsche y éste considera que esa facultad de hacer promesas - que ellos analizarán más adelante relacionándola con el perdón - es la que definitivamente distingue al hombre del animal. La influencia de Nietzsche sobre el pensamiento de nuestros autores es innegable, por lo que iniciaremos nuestra exposición con una brevísima reseña de la parte del $2^{\circ}$ Ensayo de "La Genealogía de la M oral" en la que Nietzsche aborda el tema.

De Ricoeur nos interesan especialmente sus análisis de la relación entre el perdón y los abusos de la memoria y del olvido; de la posibilidad de proyectar los procesos de la memoria impedida y de su sanación desde lo patológico - terapéutico a nivel individual al ético - político; finalmente, y a partir de lo descrito, quisiéramos caracterizar su concepto del perdón y de su fundamento.

En Arendt, por otra parte, queremos revisar principalmente el origen que atribuye al perdón y a la promesa en lo que considera las "debilidades" de la pluralidad humana; la consecuente importancia de ambas facultades dentro de la vida social y política de la humanidad e, incluso, para la preservación de los procesos naturales que condicionan la posibilidad de la vida.

Por último, procederemos a enunciar algunas consideraciones finales que junto con destacar las características atribuidas al perdón por ambos autores, enlacen y diferencien los planteamientos de ambos, indicando brevemente la importancia que atribuimos a su estudio conjunto.

\section{2.- Nietzsche y la promesa.}

A lo largo del proceso evolutivo, dice Nietzsche, la vida forjó un animal - el hombre - capaz de hacer promesas. Para ello tuvo que crear la capacidad de recordar mediante una pedagogía sangrienta, castigadora del olvido - ejercida inicialmente en el ámbito de los procesos de intercambio - tendiente a dar seguridad al acreedor en lo que respecta al pago por parte de sus deudores; se contrarrestaba, así, la fuerza de la capacidad contraria, la de olvidar, presente en el hombre independientemente de toda enseñanza y cuyo ejercicio resulta indispensable para la salud y la alegría de vivir.

Este doloroso aprendizaje hizo del hombre un extraño animal contradictorio, que como consecuencia de esa nueva facultad sería el portador - por un lado - de la enfermedad más tremenda que se ha conocido sobre la tierra, la mala conciencia o conciencia de culpa; por otro, de la extraordinaria dignidad implicada en la capacidad de decir prometo y, consecuentemente, ser responsable de sí mismo en la medida en que se hace predecible y adquiere una identidad que permite a los otros alcanzar una certeza referente a su comportamiento en el futuro.

Pero el hombre sigue necesitando el olvido, sin el cual - a semejanza de los rumiantes que mastican una y otra vez su alimento - nunca podría dar nada por terminado, por superado; de 
manera que en el animal humano sano, de voluntad fuerte, la memoria anulará el olvido solo en ciertos casos, aquellos en relación con los cuales se comprometió a mantener inalterada su conducta a lo largo del tiempo.

Vemos, así, cómo para la penetrante mirada del filósofo alemán se entrelazan olvido, castigo, memoria y promesa, pero del perdón nada nos dice.

Riceur y Arendt, en cambio, nos presentarán la facultad de perdonar - que parece desligar al hombre de sus culpas enraizadas en el pasado - como íntimamente relacionada con esa facultad de prometer magníficamente descrita por Nietzsche, que lo liga a un futuro que la promesa hace predecible.

\section{3.- Ricoeur. Memoria, Olvido y Perdón}

\section{1.- Los abusos de la memoria.}

Ejercer la memoria, vale decir recordar - nos dice Ricoeur - es usarla y el uso entraña la posibilidad del abuso. El filósofo francés revisará las dos formas fundamentales del uso de la memoria, la artificial y la natural, con el fin de descubrir en cada una de ellas los diversos abusos posibilitados por esos usos.

Cuando habla de memoria artificial, Ricoeur no se refiere a programas computacionales $u$ otros temas técnicos; se trata simplemente a una memoria no espontánea, sino expresamente cultivada.

Dentro de la memoria artificial así entendida, distingue la rememoración, consistente en un trabajo tendiente a traer a la conciencia un acontecimiento sucedido con anterioridad y no explícitamente presente en ella en ese momento y la memorización; esta última es una especie de técnica de aprendizaje que - gracias a un cierto número de repeticiones sucesivas - logra grabar en la mente ciertos conocimientos que quedan disponibles para ser utilizados de ahí en adelante por el sujeto, sin tener que volver a aprenderlos una y otra vez.

La memorización suele prestarse para una ulterior recitación de los textos considerados como fundadores de una cultura, o por lo menos de mucho prestigio al interior de ella. Este aprendizaje forma parte de la tarea propia de toda sociedad de trasmitir lo que considera como sus adquisiciones culturales, de manera que cada generación pueda evitar el esfuerzo de empezar todo de nuevo en lo que respecta a su relación con la tradición.

A partir de estos procesos de rememoración y de memorización puede producirse el deslizamiento desde el uso al abuso; porque al incentivarse la rememoración de determinados acontecimientos o al elegirse ciertas narraciones para la memorización se abre la posibilidad de instaurar un deber selectivo de memoria y, consecuentemente, puede darse un correspondiente deber de olvido, también selectivo.

Dentro de la memoria natural, por otra parte, Ricoeur distingue los abusos implicados en la memoria impedida, en la memoria manipulada, y en la memoria obligada.

La memoria impedida es una memoria herida, una memoria patológicamente imposibilitada. En relación con esta memoria enferma, Ricoeur hace uso de ciertos conceptos freudianos tales como 
el de "compulsión de repetición", generada a partir de la resistencia que la censura pone al retorno a la conciencia del hecho traumático, lo que conduce a un acto repetitivo que sustituye al recuerdo. Para lograr una "reconciliación" con lo rechazado, el analizado - con el apoyo del analista - debe emprender un "trabajo de rememoración" para intentar traer el hecho traumático a la conciencia, desplazando así la repetición compulsiva que lo sustituía.

Este proceso se inicia con lo que Freud llama "trabajo de duelo"; el "duelo" es la reacción frente a la pérdida de una persona o de una cosa amadas, pérdida que constituye el hecho traumático cuyo recuerdo es desalojado por la repetición. El "trabajo de duelo" implica la renuncia a todos y cada uno de los lazos que unían al analizado con el objeto perdido y responde a la prueba de realidad, que muestra que ese objeto amado ha dejado de existir; en esta forma, si este trabajo logra un resultado exitoso, el universo del paciente resulta empobrecido por la pérdida reconocida, pero él recupera la capacidad de recordar lo perdido, de rememorar, quedando liberado de la compulsión de repetición.

En ciertos pacientes - sin embargo - en lugar del duelo se hace presente una melancolía que los conduce al auto-reproche por una supuesta culpa frente a la pérdida, con la consecuente disminución del aprecio de sí mismos; pero en realidad estos reproches - que reflejan exigencias que el sujeto atribuye al objeto amado y perdido - ocultan quejas dirigidas a él y así convertidas en acusaciones. La melancolía exhibe, pues, el carácter ambivalente de algunas relaciones amorosas que entrelazan el amor y el odio.

Según Ricoeur, estas categorías patológicas descritas por Freud pueden ser legítimamente traspasadas al plano de la memoria colectiva en el que existen "pérdidas" que afectan al poder, al territorio, a las poblaciones, etc. En relación con ellas pueden, por consiguiente, iniciarse también trabajos de duelo que se continúen hasta la total reconciliación con el hecho traumático.

La demasiada memoria o abuso - a nivel colectivo - recuerda particularmente la compulsión de repetición que impide el recuerdo verdadero, mediante el cual el presente podría reconciliarse con el pasado.

Este abuso suele ser efecto de una manipulación ejercida por quienes detentan el poder, ayudada por el hecho de que la narraciones - que desempeñan un importante papel en la constitución de la identidad colectiva - son inevitablemente selectivas; tal como no todo puede ser recordado, no todo puede ser narrado y esto se presta a una manipulación encaminada a favorecer el olvido de ciertos aspectos y la rememoración de otros.

Dicha manipulación - dice Ricoeur - suele estar al servicio de la justificación del ejercicio del poder por parte de una facción determinada y al reforzamiento de la creencia del pueblo en la legitimidad de ese poder.

Se propicia, así, una memoria y una identidad forzadas, ayudadas por conmemoraciones acordadas, tejiéndose un pacto inconfesable entre rememoración, memorización y conmemoración.

Para sanar, la memoria colectiva herida tiene también que someterse a la prueba de realidad, vale decir, emprender el trabajo de duelo que abre camino a la rememoración liberada ya de la compulsión de repetición. 
Se configura, así, a nivel colectivo, un deber de memoria que - para no resultar equivalente a la memoria obligada constitutiva de abuso - debe incluir un elemento imperativo derivado de la idea de justicia, ausente en aquella: la exigencia de que a partir de los recuerdos traumáticos recuperados, la memoria se convierta en proyecto común, en voluntad dirigida al futuro, en promesa, para evitar la repetición de los hechos recordados.

De manera que este deber de memoria apunta fundamentalmente al bien de otros que vendrán y se relaciona estrechamente con la idea de deuda manejada por Nietzsche, que no se identifica con la de culpabilidad pero que ahora se hace además inseparable de la de herencia. Debemos parte de lo que somos a otros que ya no son, pero fueron y entre esos otros con quienes estamos endeudados, las víctimas detentan una prioridad moral que nos obliga a prometer que lo acontecido no sucederá de nuevo, nunca jamás.

En relación con lo anterior, existen indudablemente sucesos como los acaecidos en Europa y en nuestro propio país en el siglo XX, que exigen un deber de memoria. Pero decir "tú recordarás" es decir también "tú no olvidarás" y es posible que ese doble deber conduzca también en algunos casos del buen uso al abuso en el ejercicio de la memoria.

Es lo que sucede, por ejemplo, cuando la proclamación del deber de memoria queda cautiva, como sucedía en los casos de melancolía en la memoria herida a nivel del individuo, del síntoma de la repetición obsesiva que ahora se expresa a través de quienes se auto - proclaman portavoces de la exigencia de justicia de las víctimas; puede caerse, entonces, en un abuso expresado en el frenesí de conmemoraciones que - como la repetición obsesiva - obstaculiza la verdadera rememoración.

\section{2.- Los abusos del olvido}

El olvido suele sentirse en primera instancia como un atentado contra el deber de memoria que, a su vez, es percibido como una lucha contra el olvido. Pero como bien lo comprendió Nietzsche, una memoria que no olvida nada es una memoria enferma.

Ricoeur plantea que existen dos grandes formas del olvido; en primer lugar, la que obedece a una desaparición de las huellas fisiológicas y psicológicas de lo acontecido; bajo esta forma el olvido es definitivo; pero existe también el olvido de reserva o reversible.

Este último pareciera hacer referencia a la reminiscencia platónica en la que se despiertan recuerdos que el nacimiento no borró. Por su parte, Heidegger nos habla de un olvido que - lejos de impedir la memoria - la posibilita; es el olvido del pasado que ya no es, pero fue y, como tal, se ofrece como fuente inagotable al trabajo de recordar.

Los abusos de la memoria son también abusos del olvido relacionados ambos con la función mediadora del relato. El peligro mayor en este sentido deriva de la manipulación proveniente de la historia autorizada, impuesta, celebrada, conmemorada, de la historia oficial, la que va acompañada también por el correspondiente olvido de lo que no entró en la selección.

Una forma de olvido impuesto se da con la amnistía. Se la considera como una especie de perdón que puede poner fin a graves desórdenes políticos que afectan la convivencia ciudadana y a la violencia en ellos implicada. 
Ricoeur destaca la proximidad fonética y semántica existente entre amnistía y amnesia, que pareciera apuntar hacia una negación de memoria que en la amnistía parodia al perdón, pero - en realidad - lo aleja; ella representa un deber de olvido, una especie de amnesia obligada que podría privar a la memoria colectiva de una crisis de identidad - quizás implicada como consecuencia del recuerdo - conducente a una lúcida reapropiación del pasado y de su carga traumática.

Debido a ello, Ricoeur plantea que la amnistía no puede responder más que a un propósito de terapia social de urgencia, bajo el signo de la utilidad, no de la verdad. Si existiera alguna forma de olvido legítima - nos dice - no consistiría en el deber de silenciar el mal, sino la ira; consistiría en el deber de decir el mal de un modo apaciguado, sin cólera y no en obediencia a un mandato, sino como expresión de la aspiración a que el perdón sea posible.

\section{3.- El Perdón. Su existencia, Condiciones y Caracterización.}

El perdón, nos dice Ricoeur, si es que existe y tiene sentido, debiera representar una especie de horizonte hacia el que apuntan la memoria y el olvido y que - precisamente - por su condición de horizonte, se aleja ante cada paso dado en su dirección. Resulta, pues, difícil dar, recibir y concebir el perdón.

El perdón supone la imputabilidad, la posibilidad de atribuir las acciones a alguien capaz de reconocerse como responsable de sus actos y, llegado el momento, como responsable de una "falta"; esto es, de la trasgresión de una norma, de un deber y, fundamentalmente, como responsable de un daño hecho a otro. Nos encontramos, así, en el camino hacia la definición del perdón, con la noción de mal.

En el tratamiento narrativo del problema del origen del mal en los libros sagrados de Occidente, en el mito adánico por ejemplo, aparece la idea de un acontecimiento primordial - que tuvo lugar en un tiempo ajeno al de la historia - en los que el hombre perdió su inocencia originaria.

En la narración, esta pérdida aparece como un acontecimiento que pudo no haber sucedido; de modo que si desde entonces el mal representa siempre para la humanidad algo "ya allí", algo insoslayablemente presente en la experiencia, esa presencia se muestra como algo profundamente contingente.

Se expresa así una cierta distancia entre el agente y la acción, que permite concebir al primero con alguna independencia en relación con la segunda; consecuentemente, aunque la acción sea reconocida como radicalmente mala, resulta posible pensar que en el sujeto - a pesar de su adhesión al mal cometido - quede algo bueno, un resto que quizás pudiera irrumpir en alguna acción futura y con ello se abre un espacio para el perdón.

Sin embargo, el reconocimiento del ya allí del mal está tan adherido a la experiencia humana que proclamar la posibilidad del perdón puede constituirse en un desafío muy cercano a la utopía. Pero la experiencia también nos muestra que el perdón existe, a pesar de toda su dificultad; y existe no solo en el pensamiento y en la acción de carácter religioso, sino que forma parte también de la reflexión filosófica y política contemporánea, como lo ponen de manifiesto obras de autores tales como Arendt y Ricoeur mismo. 
Este último cita al respecto a Jaques Derrida, quien afirma que el perdón - si es que existe - debe dirigirse necesariamente a lo imperdonable; vale decir, tiene que ser incondicional y no esperar nada previo, ni nada a cambio; consecuentemente, debido a sus elevadas exigencias, no puede ser sino excepcional, extraordinario.

Todos sabemos que en el siglo XX se cometieron crímenes contra la humanidad, entre ellos la tortura y el genocidio, injustificables e imprescriptibles desde todo punto de vista. De manera que a diferencia del resto de los delitos cuyas consecuencias penales pueden legalmente perder vigencia después de un determinado período arbitrariamente fijado - el castigo de estos crímenes no puede ser derogado.

Estos crímenes no pueden prescribir - afirma Ricoeur - porque su prescripción implicaría una gran injusticia para las víctimas, cometida a expensas de la ley. Así, en relación con ellos debería existir un deber de memoria que incluyera el elemento normativo que ordena la proyección al futuro de su recuerdo para pagar nuestra deuda con las víctimas asegurando el nunca otra vez.

Pero lo imprescriptible y lo imperdonable no se corresponden absolutamente y es posible que el espíritu de perdón no quede enteramente desterrado del ámbito de estos crímenes; porque - a diferencia de lo que sucede con la amnistía que pretende borrar de la memoria colectiva toda huella de los delitos cometidos - aquí lo que es imprescriptible es precisamente el crimen mismo; al culpable - en cambio - en cuanto ser humano, debe concedérsele por lo menos algo que podría llamarse consideración y es lo contrario del desprecio.

Si existe el perdón, nos decía Derrida, debe ser incondicional y, por consiguiente, no puede estar subordinado a la exigencia de que haya sido solicitado. Existe en la práctica, sin embargo, la tendencia a establecer una cierta correlación entre la solicitud de perdón y el acuerdo para que éste sea concedido; cuando esto sucede, el perdón pierde su incondicionalidad y entonces se instala dentro del régimen de intercambio.

Para evitarlo, se ha aproximado la noción de perdón a la de don, entendiendo éste como la entrega a alguien, sin esperar nada a cambio, de algo que se posee o se disfruta. Supondría, pues, una falta de reciprocidad, una asimetría entre el que dona y el que recibe.

Sin embargo, hay autores que no oponen el don al intercambio mismo, sino a la forma mercantil del intercambio, en la que se hace presente el cálculo, el interés; porque un regalo hecho -dicen suscita siempre un regalo de vuelta, de manera que el don supondría un devolver; así, entendido como don el perdón perdería también su incondicionalidad.

Ricoeur, en cambio, sugiere entender el perdón a la luz de la exigencia radical de amar al enemigo, la que no incluye la existencia previa de una solicitud de perdón, contradice la ley del talión y va más allá de la Regla de Oro, que exige no hacer a los otros lo que no queremos que se nos haga. Así, cuestiona absolutamente la aspiración a la reciprocidad que podría ocultarse tras la generosidad del don, amenazando con mantenerlo en el espacio del intercambio.

Sin embargo - destaca Ricoeur - hay algo que legítimamente puede esperarse de ese don implicado en el amor al enemigo sin aproximarlo a las relaciones mercantiles: nada más y nada menos que el milagro de la transformación del enemigo en amigo. 


\section{4.- Hanna Arendt. Perdón y Promesa como Remedios para las Debilidades de la "Pluralidad".}

\section{1.- Características de la acción}

Lo que Arendt llama "vita activa" reúne tres elementos fundamentales, labor, trabajo y acción. La labor, tiende a la satisfacción de las necesidades vitales, es indispensable para el mantenimiento del proceso biológico del cuerpo humano y se agota en el cumplimiento de su función; el trabajo, da lugar a un producto, la obra, cuya duración trasciende a la de la vida de su autor; finalmente, está la acción, mediante la cual se inauguran situaciones y procesos nuevos en el mundo y da lugar a lo que la autora denomina "natalidad"; ésta es expresión de la libertad humana y contradice la comprensión heideggeriana del dassein como ser para la muerte, puesto que indica que cada hombre - aunque debe morir - con su propio nacimiento representa la irrupción de la novedad en el mundo.

Esta capacidad de natalidad que es propia de la condición humana esencial, se expresa en la "pluralidad"; esto es, en el hecho de que los hombres - siendo todos iguales en cuanto son humanos - no son jamás idénticos entre sí; de manera que nunca surge uno que repita a otro que haya vivido en el pasado, viva en la actualidad, o vaya a vivir en el futuro. La natalidad implica, pues, la pluralidad y ésta exige la integración de los diferentes.

\section{2.- Perdón y Promesa.}

El perdón y la promesa - afirma Arendt - son necesarios debido a las "debilidades" propias de la condición humana, derivadas de esa pluralidad que la define. Ellas consisten, en primer lugar, en la incertidumbre proveniente del temor ante la irreversibilidad de las consecuencias desatadas por la novedad de la acción, que se multiplican indefinidamente y sobre las cuales - finalmente carecemos de dominio; en segundo lugar, en la impredictibilidad del comportamiento humano, que hace que las conductas futuras se constituyan en una incógnita. Realmente - afirma Arendt - tal como dice Jesús de Nazareth en referencia a quienes participaron en el proceso conducente a su muerte, "los hombres no saben lo que hacen".

El perdón responde a la primera debilidad, en la medida que nos desliga de las consecuencias irreversibles de nuestros actos del pasado; la promesa responde a la segunda, en cuanto al obligarnos a mantener lo prometido, remedia la imposibilidad de predecir lo que haremos en el futuro. Mientras la última nos liga haciéndonos dueños de nosotros mismos, el primero nos desliga, permitiéndonos recomenzar la acción, posibilitando la natalidad.

Si no contáramos con el perdón liberador, quedaríamos para siempre amarrados a un solo acto, de cuyas consecuencias indefinidamente multiplicadas, jamás podríamos liberarnos. Sin la obligación de cumplir nuestras promesas, careceríamos de la identidad que se ve confirmada en la esfera pública por los otros que reconocen en cada uno la correspondencia entre el que promete y el que cumple.

Así, la capacidad de perdonar y de hacer promesas representan - como lo anunciara el título de nuestro trabajo - las condiciones de posibilidad de nuestra libertad en la medida en que nos permiten, a la vez, iniciar procesos nuevos en el mundo y construir nuestra identidad. 
Para Arendt, el perdón, como respuesta a una de las debilidades de la acción, no presenta el carácter excepcional que le atribuye Ricoeur en concordancia con lo planteado por Derrida.

Pero ella, en cambio, especifica explícitamente lo que sería imperdonable: el mal radical, cuya radicalidad se expresa en una banalidad que lo hace imperceptible para quien lo comete; la maldad de un Eichmann, por ejemplo, que considera que en toda su vida no ha hecho más que cumplir con su deber, que se dice kantiano y, como tal, respetuoso del imperativo categórico. Su maldad es imperdonable, porque esa banalidad del mal indicaría que quien la vive es incapaz de pensar, no conoce la "solitud"; vale decir, no ha practicado el diálogo consigo mismo, no para definir lo que debe hacer, sino lo que "no puede hacer" si quiere poder convivir consigo mismo y conservar la condición humana; debido a esa incapacidad, el deber queda definido para él exclusivamente por la ley, por el mandato de la autoridad, independientemente de su contenido.

En este caso, aunque Arendt no lo dice con estas palabras, quizás no se podría perdonar porque como lo plantea Ricoeur - el perdón solo puede ejercerse en relación con un ser capaz de imputación; vale decir, en relación con el ser humano y el que carece de la capacidad de pensar no participa de esa condición.

\section{3.- La Irreversibilidad y la Impredictibilidad Introducidas en la Naturaleza por la Técnica.}

Aunque no guarda una relación directa con el tema del perdón, creo conveniente introducir brevemente la reflexión de Arendt referente al contagio - podría decirse - de los fenómenos naturales con las debilidades de la pluralidad humana; porque dicha reflexión hace referencia al concepto del poder propio de Arendt, que lo concibe enraizado en el querer vivir juntos de los miembros de una comunidad, que conciertan sus voluntades en función de metas comunes. Incumbe, pues, al contrato y a la promesa, íntimamente ligados a nuestro tema del perdón.

La ciencia y la tecnología contemporáneas, que ya no se limitan a la observación e imitación de los procesos naturales, sino que los intervienen directamente, parecen introducir en medio de la sucesión cíclica de dichos procesos, la irreversibilidad e imprevisibilidad propias del carácter lineal de la temporalidad humana.

Pero en la esfera natural no existe la posibilidad de recurrir al perdón ni a la promesa para deshacer - o por lo menos atenuar - lo que el hombre ha hecho; se corre, pues, el riesgo de que esas debilidades propias de la pluralidad humana - al desplazar los ciclos siempre iguales a sí mismos del llegar a ser y del dejar de ser - afecten las condiciones mismas que hicieron posible la vida humana sobre la tierra.

Para contrarrestar ese riesgo, habría que cultivar esa forma originaria del poder que se genera en el contrato y la promesa mutua solo posibles entre seres humanos capaces de perdonarse y de mantener la concertación de voluntades, único origen legítimo del poder, que se desintegra cuando esa concertación desaparece.

\section{5.- Consideraciones finales.}


El perdón, plantea Ricoeur, necesita de la rememoración para que los hechos traumáticos no vuelvan a repetirse; pero requiere también de la capacidad de olvido implicada en el trabajo de duelo para lograr la superación de la repetición obsesiva que sustituye al auténtico recuerdo.

Debe ser incondicional - como lo es el amor al enemigo - para no reducirse a una mera forma de intercambio y mantener así la asimetría entre el que perdona sin esperar nada a cambio y el que es perdonado, asimetría cuyo reconocimiento se constituye en el motor del milagro de la conversión en amigo del que fuera enemigo. La relación del perdón con esa forma de amor tan exigente lo constituye en algo extraordinario y difícil, pero no imposible.

Esta incondicionalidad del perdón es factible para Ricoeur debido a la distancia que él supone existente entre el agente y su acción, porque esa distancia permite perdonar al primero sin olvidar ni perdonar el crimen.

Para Arendt, el perdón, al igual que la promesa, es simplemente una facultad humana tendiente a remediar las debilidades implicadas en lo que representa la verdadera esencia del hombre, la pluralidad; por consiguiente, no presenta la dificultad, ni deben esperase de él los efectos milagrosos que Ricoeur le atribuye. Perdón y promesa no son más que las respuestas necesarias para que la pluralidad, esto es, la concertación de los individuos diversos a partir de su básica igualdad de seres humanos, pueda ejercerse en la creación de identidad y novedad.

Arendt, por otra parte, no reconoce la incondicionalidad del perdón postulada por Ricoeur, puesto que señala una forma de mal imperdonable: la de esos hombres que - para espanto de las generaciones que los siguieron - banalizaron el mal hasta el extremo de no reconocerlo en ellos mismos.

Sin embargo, en lo que a esto respecta, la distancia entre ambos pensadores podría ser menor de lo que parece a primera vista. Arendt considera imperdonables a esos hombres, porque no llegaron a ejercer la "solitud", ese diálogo interior tendiente a definir lo que no se puede hacer si se pretende conservar la propia humanidad. No se los puede perdonar, entonces, porque el perdón es una relación entre seres humanos y ellos no llegaron a serlo.

Ricoeur, por su parte, si bien postula la incondicionalidad del perdón, plantea que para que el perdón exista, es necesario que haya quienes se reconozcan responsables de sus actos y de sus consecuencias, esto es, quienes sean imputables; es decir, plantea que para que exista el perdón es necesario que haya hombres.

Así, la aparente discordancia se convierte en coincidencia: para ambos el perdón solo es posible en relación con seres humanos; pero, a pesar de todo se mantiene una diferencia.

Para Ricoeur la condición humana es indeleble porque existe una distancia entre el agente y la acción que permite conservarla, para Arendt - en cambio - han existido hombres que carecieron de humanidad y son, por consiguiente, imperdonables.

Me atrevería a decir que esta diferencia surge a partir de la fe religiosa de Ricoeur y de la condición agnóstica de Arendt; ella - sin embargo - no representa en absoluto un impedimento para la mutua complementación de sus respectivos planteamientos que coinciden en un punto central: el perdón nos libera de las cadenas del pasado, pero la promesa nos ata a un futuro con el que nos compromete y del que debemos responder. En esta coincidencia se expresa el riquísimo aporte 
de ambos a nuestra reflexión y al ulterior ejercicio posible de un diálogo sobre el perdón y la promesa, que integre en torno a acuerdos comunes la esencial pluralidad constitutiva de la comunidad nacional.

\section{Bibliografía.}

Arendt, Hanna.

- De la Historia a la Acción. Paidos. Barcelona. 1995.

- La Condición Humana. Paidos. Barcelona. 1993.

Ricoeur, Paul.

- La Memoire, L'Histoire, L'Oubli. Editions du Seuil. Paris 2000.

- Caminos del Reconocimiento. Fondo de Cultura Económica, México 2006. 